\title{
Changes of the Video Head Impulse Test Gains by the Directions of Head Rotation at Different Target Distances and Rotation Speeds
}

\author{
Chan Il Song1, Yeong Eun Kim², Eun Hye Cha ${ }^{2}$, \\ Myung Hoon $\mathrm{Yoo}^{3}$, Je Yeon Lee', and Hong Ju Park ${ }^{2}$ \\ ${ }^{1}$ Department of Otolaryngology-Head and Neck Surgery, Jeju National University School of Medicine, Jeju; and \\ ${ }^{2}$ Department of Otolaryngology-Head and Neck Surgery, Asan Medical Center, University of Ulsan College of Medicine, Seoul; and \\ ${ }^{3}$ Department of Otolaryngology-Head and Neck Surgery, Korea University Ansan Hospital, Ansan, Korea
}

\section{머리의 회전 속도와 시선 고정 거리, 머리 회전 방향에 따른 비디오 두부충동검사에서의 전정안반사 이득의 변화}

송찬일 $^{1} \cdot$ 김영은 $^{2} \cdot$ 차은혜 $^{2} \cdot$ 유명훈 $^{3} \cdot$ 이제연 ${ }^{2} \cdot$ 박홍주 $^{2}$

제주대학교 의학전문대학원 이비인후과학교실, ${ }^{1}$ 울산대학교 의과대학 서울아산병원 이비인후과학교실, ${ }^{2}$ 고려대학교 의과대학 안산병원 이비인후과학교실 ${ }^{3}$

\author{
Received April 4, 2015 \\ Revised May 5, 2015 \\ Accepted May 18, 2015 \\ Address for correspondence \\ Hong Ju Park, MD, PhD \\ Department of Otolaryngology- \\ Head and Neck Surgery, \\ Asan Medical Center, \\ University of Ulsan \\ College of Medicine, \\ 88 Olympic-ro 43-gil, Songpa-gu, \\ Seoul 138-736, Korea \\ Tel $+82-2-3010-3700$ \\ Fax $+82-2-489-2773$ \\ E-mail dzness@amc.seoul.kr
}

Background and Objectives The conventional instrument for video head impulse test (vHIT) records the movement of the right eye only. The aim of this study was to evaluate the changes in the gain of vHIT results qdue to different directions of head rotation directons at different target distances and rotation speeds.

Subjects and Method Horizontal head impulse was recorded by vHIT in 20 normal subjects. vestibulo-ocular reflex (VOR) gains to the right and left directions were compared at different test conditions. Two different impulses with low (50-150 deg/sec) and high (200-300 deg/sec) peakhead-velocities were tested and the subjects were also instructed to fixate a laser dot on a screen at different distances of 60,100 , and $200 \mathrm{~cm}$. Eye movements were recorded on the right eye.

Results Regardless of the target distances and peak-head-velocities, the VOR gains to the rightward head rotation were significantly greater than those to the leftward head rotation. In more than $85 \%$ of normal subjects, vHIT gain to the rightward head rotation was greater than that to the leftward head rotation. Mean gain asymmetries were $2.16-3.33 \%$ and the mean interaural vHIT gain differences were $0.04-0.07$.

Conclusion Regardless of the target distances and peak-head-velocities, the VOR gains to the rightward head rotation were significantly greater than those to the leftward head rotation. Directional asymmetry of VOR gain should be considered when interpreting vHIT results in patients with vestibular disorders. Korean J Otorhinolaryngol-Head Neck Surg 2015;58(8):547-51

Key Words Interaural difference - Vestibule-ocular reflex · Video head impulse test.

\section{서 론}

측반고리관의 기능을 검사하는 온도안진검사나 회전의자검 사는 저주파 영역에서의 전정안반사(vestibulo-ocular reflex) 를 측정하기 때문에 일상 생활에서의 전정안반사를 반영하
는 데 한계가 있으나, 두부충동검사(head impulse test)는 상 대적으로 고주파 영역에서의 전정안반사를 평가할 수 있는 방법으로서 임상에서 손쉽게 시행할 수 있는 유용한 검사이 다. 최근 개발되어 임상에서 사용되고 있는 비디오 두부충동 검사(video head impulse test, vHIT)로 인해 객관적이면서 
도 안전하고 간단하게 전정안반사를 기록할 수 있게 되었으 며, 이 장치는 말초 전정기능 장애를 진단함에 있어서 기존의 가장 정확한 검사 결과를 제시할 수 있는 것으로 알려진 공막 자기장 추적 장치(sclera magnetic search coil system)를 이용 한 검사와 동일한 결과를 보여주는 것으로 알려져 있다. ${ }^{1,2)}$

그런데 상용화되어 국내에서 사용되고 있는 비디오 두부충 동검사 기기(ICS Impulse ${ }^{\circledR}$, GN Otometrics, Taastrup, Denmark)는 우측 눈에서만 안구의 움직임을 측정하게 되어 있다. 우측 눈을 기준으로 하였을 때, 머리를 좌측으로 돌릴 때에는 안구를 외측으로 향하게 하기 위해 외직근(lateral rectus muscle)이 작용하고 머리를 우측으로 돌릴 때에는 안구를 내측 으로 향하게 하기 위해 내직근(medial rectus muscle)이 작용 한다. 안구 운동을 유발하는 외안근이 머리 회전 방향에 따 라 다르며 각각의 외안근들의 형태와 위치가 상이하다는 것 을 고려하면, 한쪽 눈에서만 안구의 움직임을 측정하는 비디 오 두부충동검사 기기를 이용했을 때 머리 회전 방향에 따라 서 전정안반사의 이득(gain)이 다르게 나올 가능성이 있다.

따라서 본 연구에서는 상용화되어 있는 비디오 두부충동 검사를 이용하여 정상인에서 좌, 우측으로 머리를 회전했을 때의 이득의 차이가 있는지 알아보고, 시선을 고정시키는 목적 점(target point)의 거리를 다르게 하였을 때 내직근과 외직근 에 의한 이득의 차이에 변화가 있는지를 알아보고자 하였다.

\section{대상 및 방법}

\section{대 상}

문진과 고막 검사에서 이상 소견이 없었으며, 어지럼증과 난청을 포함한 이과적 질환이 없고 신경 안정제 등 전정기능 에 영향을 주는 약물 등을 복용하지 않는 만 19세 이상 40세 이하의 건강한 20 명의 정상인을 대상으로 연구를 시행하였다. 시력에 이상이 있어 안경을 사용하는 연구 대상자는 안경을 벗고 연구에 참여하였고, 안경을 벗었을 때 약 $200 \mathrm{~cm}$ 앞에 있 는 표적이 보이지 않는 대상자는 연구에서 제외하였다.

\section{방 법}

20명의 대상자에서 수평 방향으로 두부충동을 시행하였으 며 비디오 두부충동검사 기기는 ICS Impulse ${ }^{\circledR}$ (GN Otometrics, Taastrup, Denmark)를 사용하였고 안진의 측정은 우측 안 구에서만 시행되었다. 머리의 회전은 양쪽으로 각각 $5 \sim 10^{\circ}$ 의 급속한 회전자극을 10 회씩 주었으며, 검사자가 피실험자의 뒤쪽에서 피실험자의 머리를 잡은 상태로 피실험자가 방향과 시간을 예상하지 못 하도록 무작위적으로 시행하였다. 피실험 자의 머리를 돌리는 속도는 느린 머리 회전속도(low peak- head-velocity, 50 150 deg/sec)와 빠른 머리 회전속도(high peak-head-velocity, 200 300 deg/sec)의 두 가지 속도로 시 행하였다. 피실험자의 시선을 고정시키는 거리는 $100 \mathrm{~cm}$ 앞에 시선을 고정하도록 하는 기존의 검사 방법과 함께, 피실험자로 부터 $60 \mathrm{~cm}$ 전방에 시선을 고정하도록 하여 두부충동검사를 시행하는 방법과 $200 \mathrm{~cm}$ 전방에 시선을 고정하도록 지시한 후 다시 두부충동검사를 시행하는 방법으로 연구를 진행하였다. 검사의 신뢰도를 위해 1 명의 검사자가 모든 피실험자에게 검 사를 시행하였고, 피실험자의 머리를 돌리는 속도를 일정하게 유지하고 좌우 방향에 의한 비대칭이 발생하지 않도록 충동을 실시할 때마다 실시간으로 머리 회전 속도를 피드백해 주었다. 이득은 머리가 움직이는 정도와 안구의 움직이는 정도를 비 교하여 계산되며, 기기에 내장된 프로그램을 이용하여 구하였 다. 이득은 시간에 따른 머리와 안구의 속도를 측정하여 머리 회 전운동이 시작된 후 머리의 운동속도가 0 이 되는 점까지의 머 리의 움직인 면적과 안구의 움직인 면적을 비교하여 계산된다. ${ }^{3)}$

머리의 회전자극을 좌우로 줄 때의 차이를 확인하기 위한 이득 비대칭(gain asymmetry) 값은 다음과 같은 공식을 이 용하여 계산하였다. ${ }^{4}$ 이득 비대칭 값이 양의 값을 보일 경우 우측으로 회전자극을 줄 때의 비디오 두부충동검사 이득이 좌측으로 회전자극을 줄 때의 비디오 두부충동검사 이득보 다 더 큼을 의미한다.

$$
\text { Gain asymmetry }(\%)=\frac{(G r-G l)}{(G r+G l)} \times 100
$$

(Gr: Vestibulo-ocular reflex gain when head was rotated to the right, Gl: Vestibulo-ocular reflex gain when head was rotated to the left)

\section{통계분석}

통계분석은 PASW ${ }^{\circledR}$ Statistics $18(S P S S$ Inc., Chicago, IL, USA) 소프트웨어를 사용하였다. 우측과 좌측으로 머리를 회전하였 을 때 각각의 전정안반사 이득을 측정하였으며, 각 군에서의 차이 를 비교하기 위해 이득의 평균값을 Wilcoxon signed ranks test를 이용하였으며, $p$ 값은 0.05 이하를 의미 있는 것으로 해석하였다.

\section{임상시험심의위원회}

본 연구는 서울아산병원 임상연구심의위원회(Institutional Review Board)의 승인을 얻은 후 시작되었다.

\section{결 과}

본 연구에 참여한 20 명의 대상자 중 남자는 9 명, 여자는 11 
명이었으며, 만 24세에서 만 34세까지 분포하고 있었다. 통상 거리 $(100 \mathrm{~cm})$ 표적에 시선을 고정시키는 기존의 방법으로 두 부충동검사를 시행한 10 명은 남자 2 명과 여자 8 명으로 구성 되었으며, 나이는 만 26세에서 만 34세까지 분포하고 있었다.

\section{표적의 거리와 자극 정도에 따른 비디오 두부충동검사 이득의 변화}

$100 \mathrm{~cm}$ 표적에 시선을 고정시키고 느린 속도로 머리를 회 전시켰을 때, 우측으로 회전자극을 줄 때의 비디오 두부충동 검사 이득 $(1.02 \pm 0.09)$ 이 좌측으로 회전자극을 줄 때의 비디 오 두부충동검사 이득 $(0.96 \pm 0.05)$ 보다 컸으나, 통계적으로 유 의하지는 않았다 $(p=0.139)$ (Fig. 1, Table 1). 빠른 속도로 두부 충동을 시행한 경우에도 우측으로 회전자극을 줄 때의 비디 오 두부충동검사 이득(1.02 \pm 0.04$)$ 이 좌측으로 회전자극을 줄 때의 비디오 두부충동검사 이득 $(0.96 \pm 0.07)$ 보다 컸으며 이는 통계적으로도 유의한 차이를 보였다 $(p=0.011)$ (Fig. 1, Table 1).

$60 \mathrm{~cm}$ 표적에 시선을 고정시키고 느린 속도로 두부충동검 사를 시행하였을 때, 우측으로 회전자극을 줄 때의 비디오 두부충동검사 이득 $(1.01 \pm 0.07)$ 이 좌측으로 회전자극을 줄 때의 비디오 두부충동검사 이득 $(0.96 \pm 0.07)$ 보다 컸으며 $(p=0.005)$, 빠른 속도로 두부충동검사를 하였을 때도 우측

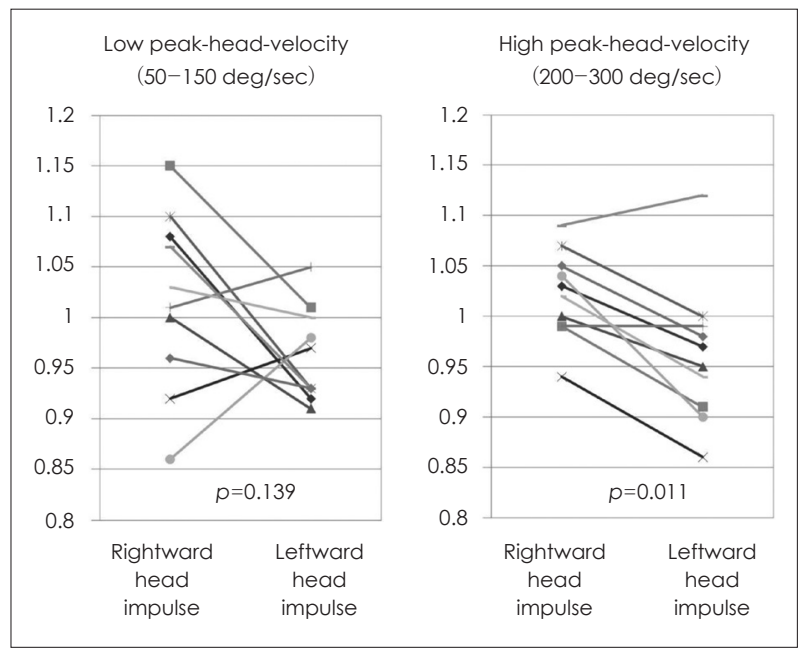

Fig. 1. Vesitbulo-ocular reflex gains of ten subjects with low and high peak-head-velocity at usual target distance $(100 \mathrm{~cm})$.
으로 회전자극을 줄 때의 비디오 두부충동검사 이득(1.01土 0.05)이 좌측으로 회전자극을 줄 때의 비디오 두부충동검사 이득 $(0.95 \pm 0.06)$ 보다 컸다 $(p<0.001)$ (Fig. 2).

$200 \mathrm{~cm}$ 표적에 시선을 고정하고 느린 속도로 회전한 경우 도 우측으로 회전자극을 줄 때의 비디오 두부충동검사 이득 $(1.00 \pm 0.06)$ 이 좌측으로 회전자극을 줄 때의 비디오 두부충 동검사 이득 $(0.94 \pm 0.04)$ 보다 더 컸으며 $(p<0.001)$, 빠른 속도 의 두부충동검사에서도 우측으로 회전자극을 줄 때의 비디 오 두부충동검사 이득 $(0.98 \pm 0.09)$ 이 좌측으로 회전자극을 줄 때의 비디오 두부충동검사 이득 $(0.93 \pm 0.06)$ 보다 큰 값을 보였다( $p=0.005)$ (Fig. 3).

\section{표적의 거리와 자극 정도에 따른 비디오 두부충동검사 이득의 비대칭 차이}

$100 \mathrm{~cm}$ 의 표적에 시선을 고정한 상태에서 이득 비대칭 값

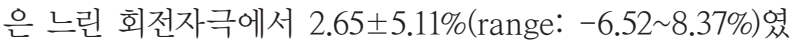
고, 빠른 회전자극에서 $3.10 \pm 2.38 \%$ (range: $-1.36 \sim 7.22 \%$ )였 다. 느린 회전자극에서는 정상인의 $70 \%$, 빠른 회전자극에서 는 정상인의 $80 \%$ 에서 우측으로 머리 회전자극을 줄 때의 비 디오 두부충동검사 이득이 좌측으로 자극할 때의 비디오 두 부충동검사 이득보다 컸다. 우측과 좌측을 자극할 때의 비디

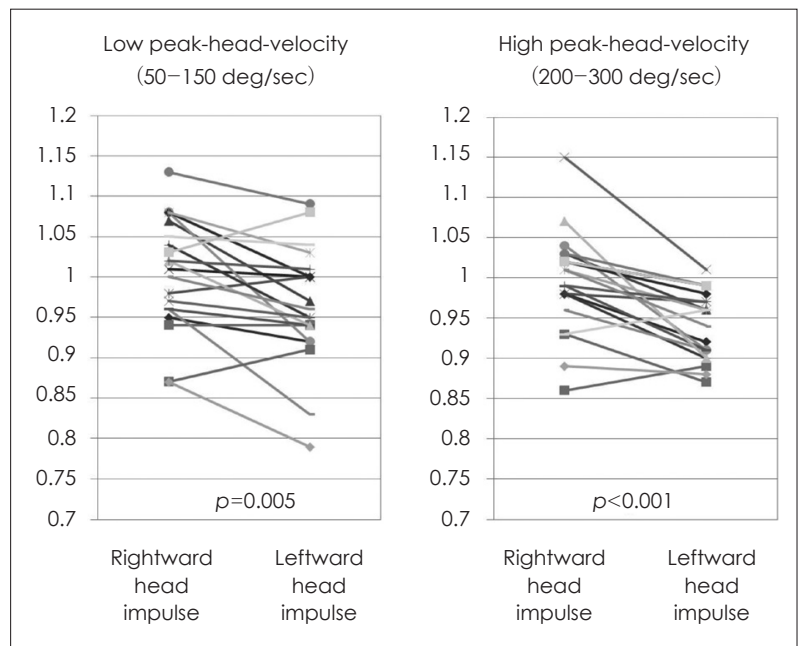

Fig. 2. Vesitbulo-ocular reflex gains of twenty subjects with low and high peak-head-velocity at near target distance $(60 \mathrm{~cm})$.

Table 1. Changes of the video head impulse test gains by the directions of head rotation at different target distances and rotation speeds

\begin{tabular}{ccccc}
\hline Target distance & Peak head velocity & Gain, rightward & Gain, leftward & $p$-value \\
\hline \multirow{2}{*}{$60 \mathrm{~cm}$} & $50-150 \% \mathrm{sec}$ & $1.01 \pm 0.07$ & $0.96 \pm 0.07$ & 0.005 \\
& $200-300 \% \mathrm{sec}$ & $1.01 \pm 0.05$ & $0.95 \pm 0.06$ & $<0.001$ \\
\multirow{2}{*}{$100 \mathrm{~cm}$} & $50-150 \% \mathrm{sec}$ & $1.02 \pm 0.09$ & $0.96 \pm 0.05$ & 0.139 \\
& $200-300 \% \mathrm{sec}$ & $1.02 \pm 0.04$ & $0.96 \pm 0.07$ & 0.011 \\
$200 \mathrm{~cm}$ & $50-150 \% \mathrm{sec}$ & $1.00 \pm 0.06$ & $0.94 \pm 0.04$ & $<0.001$ \\
& $200-300 \% \mathrm{sec}$ & $0.98 \pm 0.09$ & $0.93 \pm 0.06$ & 0.005 \\
\hline
\end{tabular}




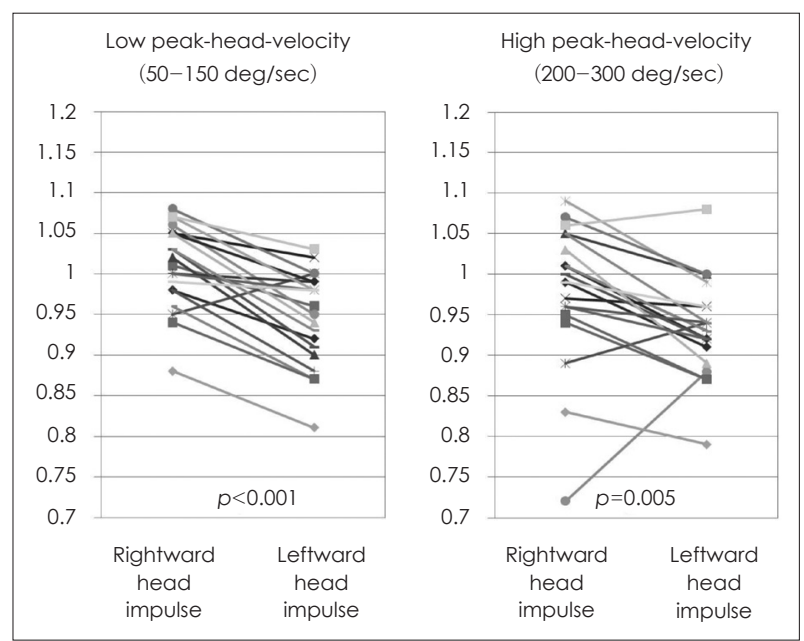

Fig. 3. Vesitbulo-ocular reflex gains of twenty subjects with low and high peak-head-velocity at far target distance $(200 \mathrm{~cm})$.

오 두부충동검사 이득의 차이는 느린 회전자극에서는 평균 0.06(range: -0.12 0.17)의 차이를 보였고 빠른 회전자극에 서는 평균 0.06(range: -0.03 1.07)의 차이를 보였다. $60 \mathrm{~cm}$ 의 근거리 표적에 시선을 고정한 상태에서 이득 비대칭 값은, 느린 회전자극에서 2.16 $2.84 \%$ (range: -2.37 8.00\%)였고,

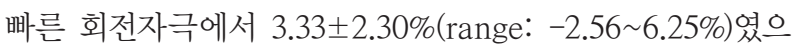
며, 느린 회전자극에서는 정상인의 $85 \%$, 빠른 회전자극에서 는 정상인의 $95 \%$ 에서 우측으로 머리 회전자극을 줄 때의 비 디오 두부충동검사 이득이 좌측을 자극할 때의 비디오 두부 충동검사 이득보다 컸다. 우측과 좌측을 자극할 때의 비디오 두부충동검사 이득의 차이는 느린 회전자극에서는 평균 0.04(range: -0.05 0.12)의 차이를 보였고 빠른 회전자극에 서는 평균 0.07(range: -0.05 0.12)의 차이를 보였다. 200 $\mathrm{cm}$ 의 원거리 표적에 시선을 고정했을 때, 이득의 비대칭 값 은 느린 회전자극에서 $2.74 \pm 2.57 \%$ (range: -1.71 8.63\%)였 고, 빠른 회전자극에서 2.35 $3.71 \%$ (range: -10.00 7.29\%)였 으며, 느린 회전자극에서는 정상인의 $90 \%$, 빠른 회전자극에 서는 정상인의 $85 \%$ 에서 우측으로 머리 회전자극을 줄 때의 비디오 두부충동검사 이득이 좌측을 자극할 때의 비디오 두 부충동검사 이득보다 컸다. 우측과 좌측을 자극할 때의 비디 오 두부충동검사 이득의 차이는 느린 회전자극에서는 평균 0.05(range: -0.03 0.17)의 차이를 보였고 빠른 회전자극에 서는 평균 0.05(range: -0.16 0.14)의 차이를 보였다.

\section{고 찰}

본 연구의 결과에 따르면 정상인에서 한쪽 눈에서만 안진 을 측정하는 경우 두부충동검사에서 머리를 회전시키는 방 향이 우측이냐 좌측이냐에 따라 전정안반사의 이득은 비대
칭을 보였으며, 시선을 고정시키는 거리를 변화시키거나 머리 회전 자극의 크기와 관계없이 동일한 결과를 얻을 수 있었 다. 본 연구에서 사용한 기기와 같이 우측 안구에서만 안진 을 측정하는 경우, 정상인의 경우에는 우측으로 두부충동을 주었을 때의 이득이 좌측으로 두부충동을 주었을 때의 이득 보다 유의하게 컸다.

공막 자기장 추적 장치를 이용한 연구에서도 본 연구결과 와 유사한 결과를 보고하였다. ${ }^{5}$ 이 연구에 따르면, 면적을 이 용한 머리와 안구의 움직인 거리를 비교한 본 연구와 다르게 머리나 안구의 움직이는 가속도의 차이를 이용하여 이득을 비교하였으며, 낮은 가속도의 머리 회전운동에서는 이러한 차이가 크지 않았으나 머리 회전자극의 가속도가 커질수록 이러한 차이가 커짐을 보고하였다. 최근에 보고된 비디오 두 부충동검사 기기를 이용한 연구에서도 유사한 결과가 보고 되었다. ${ }^{6}$ 본 연구에서는 머리회전 자극의 크기와 표적의 거리 에 상관없이 모든 경우에서 우측을 향하는 머리 회전자극에 서 비디오 두부충동검사 이득이 좌측을 향하는 회전자극에 대한 비디오 두부충동검사 이득보다 높았으며, 임상적으로 사용되는 $100 \mathrm{deg} / \mathrm{sec}$ 이상의 머리 회전자극에서는 좌우의 비디오 두부충동검사 이득 차이가 의미 있게 날 수 있음을 알 수 있었다.

본 연구에서는 우측 안구의 움직임을 측정하였으므로, 우 측으로 머리를 회전할 때의 비디오 두부충동검사 이득이 더 큰 원인은 내직근이 외직근보다 더 강한 안구운동을 유발하 든지, 안구 운동이 자극을 받은 수평 반고리관으로부터 동 측 안구의 내전을 일으키는 내직근(medial rectus muscle)까 지의 신경 경로(synaptic pathway)가 더 효과적이기 때문이 라고 생각할 수 있다. 실제로, 내직근과 외직근의 근력의 차 이가 있음이 보고되었으며, 인체에서 내직근의 동적 수축력 (active force)의 최대치는 외직근의 최대 동적 수축력보다 약 $26 \%$ 더 크다는 것이 보고되었다.,7) 이러한 전정안반사의 이득 비대칭은 자극을 받은 수평 반고리관으로부터 동측의 내직근(medial rectus muscle)까지의 경로 상에서 외전신경 핵간 뉴런(abducens internuclear neuron)의 발화율의 차이 에 의한 현상의 가능성을 제시하는 연구자들도 있다. ${ }^{5,8,9}$ 공 막 자기장 추적 장치를 이용하여 정상인의 양측 안구에서의 두부충동검사 이득을 측정한 결과를 보면, 두부충동검사의 이득이 양측에서 대칭적이었던 것으로 보암) 인간 대뇌의 좌반구와 우반구가 기능적으로 비대칭이라는 것, 연구 대상 자들인 오른손잡이인지 왼손잡이인지 등에 의한 영향은 배 제할 수 있을 것으로 판단된다. 또, 연구 대상자들의 시력이 두 부충동검사의 결과에 영향을 줄 가능성도 있다. 이 연구에서 는 안경 등의 시력교정 장비를 제거한 상태에서 연구를 시행 
하였고 시력교정 장비를 제거했을 때 $200 \mathrm{~cm}$ 앞의 표적이 보 이지 않을 정도로 시력이 좋지 않은 경우는 연구 대상자에서 제외하였다. 근시, 난시, 원시 등 시력에 이상이 있는 사람들 이 다수 있음을 고려할 때 차후에는 시력이 두부충동검사에 미치는 영향에 대한 연구도 필요할 것으로 판단된다.

이 연구의 결과를 바탕으로 비디오 두부충동검사 장치를 이용한 두부충동검사에서 이득과 이득 비대칭 값의 정상범 위[mean \pm 2 standard deviation(SD)]를 추정한다면, 이득은 0.8 이상, 이득 비대칭 값은 $-5 \sim 10 \%$ 로 추정할 수 있다. 본 연 구에서의 이득은 기기 회사와 비디오 두부충동검사를 이용 한 보고에서 사용되는 값과 일치함을 알 수 있다." 공막 자기 장 추적 장치와 비디오 두부충동검사 기기를 이용한 연구에 서 $95 \%$ 신뢰구간(mean $\pm 2 \mathrm{SD})$ 을 통하여 정상 이득의 최저 값 이 0.68 0.84임이 보고되었으며, ${ }^{11-14)}$ 비디오 두부충동검사 기 기를 이용한 연구에서 이득 비대칭 값의 정상 범위는 $10 \%$ 이 내였으며, ${ }^{15)}$ 공막 자기장 추적를 이용한 연구에서 $99 \%$ 신뢰 구간 $(\mathrm{mean} \pm 3 \mathrm{SD})$ 을 통하여 이득 비대칭 값의 정상 범위를 $\pm 5.8 \%$ 이내로 추정하였던 연구와 비교하였을 때, ${ }^{10)}$ 비디오 두부충동검사 기기가 공막 자기장 추적 장치를 이용한 결과 와 유사한 결과를 보이는 것으로 생각된다. 따라서, 공막 자 기장 추적 장치에 비하여 간편하고 짧은 시간에 간단히 시행 할 수 있다는 장점과 전정 신경염이나 약물에 의한 전정 기 능 장애를 진단함에 있어서 공막 자기장 추적 장치와 동일한 정확도를 보였다는 보고를 고려할 때, ${ }^{1,16)}$ 비디오 두부충동검사 기기의 유용성은 명백하다. 그러나, 본 연구에서 확인된 바와 같이 한쪽 안구만을 이용하여 검사를 시행할 경우 어느 방향 으로 두부충동을 주느냐에 따라서 이득의 비대칭이 확인되 기 때문에 검사 결과를 해석할 때 이득의 비대칭이 존재함을 염두에 두어야 하며, 향후 양측의 안구의 움직임을 고려한 이 득의 계산이 보다 정확한 검사 결과를 보여줄 것으로 생각된다.

결론적으로, 시선을 고정시킨 거리 및 머리의 회전 속도와 무관하게, 내직근에 의해서 전정안반사가 일어나는 방향의 전정안반사의 이득이 외직근에 의해서 일어나는 방향의 이 득보다 컸다. 좌측과 우측으로 두부충동을 하였을 때, 이득 의 차이는 상황에 따라 최대 0.17 까지 차이를 보였다. 정상인 에서 이득의 정상 범위는 0.8 이상, 정상인에서 우측의 이득이 상대적으로 크게 나올 수 있기 때문에 이득 비대칭 값의 정상 범위는 $-5 \sim 10 \%$ 이내였다. 따라서, 임상에서 우측 안구에서
만 안진을 측정하는 비디오 두부충동검사 기기를 사용하여 전정기능을 평가할 때, 우측으로 두부충동을 하는 경우에 좌측으로 두부충동을 했을 때보다 정상적으로 이득이 크게 나온다는 것을 고려하여 판단해야 하겠다.

\section{REFERENCES}

1) MacDougall HG, Weber KP, McGarvie LA, Halmagyi GM, Curthoys IS. The video head impulse test: diagnostic accuracy in peripheral vestibulopathy. Neurology 2009;73(14):1134-41.

2) Bartl K, Lehnen N, Kohlbecher S, Schneider E. Head impulse testing using video-oculography. Ann N Y Acad Sci 2009;1164:331-3.

3) Barin K. ICS Impulse vHIT: Interpretation of test results [cited 2014 Oct 1]. Available from: URL: http://icsimpulse.com/blog/icsimpulse-vhit-interpretation-of-test-results.

4) Mahringer A, Rambold HA. Caloric test and video-head-impulse: a study of vertigo/dizziness patients in a community hospital. Eur Arch Otorhinolaryngol 2014;271(3):463-72.

5) Weber KP, Aw ST, Todd MJ, McGarvie LA, Pratap S, Curthoys IS, et al. Inter-ocular differences of the horizontal vestibulo-ocular reflex during impulsive testing. Prog Brain Res 2008;171:195-8.

6) Matiño-Soler E, Esteller-More E, Martin-Sanchez JC, MartinezSanchez JM, Perez-Fernandez N. Normative data on angular vestibulo-ocular responses in the yaw axis measured using the video head impulse test. Otol Neurotol 2015;36(3):466-71.

7) Collins CC, Carlson MR, Scott AB, Jampolsky A. Extraocular muscle forces in normal human subjects. Invest Ophthalmol Vis Sci 1981;20(5):652-64.

8) Nakao S, Sasaki S, Shimazu H. Nuclear delay of impulse transmission in abducens motoneurons during fast eye movements of visual and vestibular origin in alert cats. J Neurophysiol 1977;40(6):1415-23.

9) Highstein SM, Holstein GR. The anatomy of the vestibular nuclei. Prog Brain Res 2006;151:157-203.

10) Park HJ, Migliaccio AA, Della Santina CC, Minor LB, Carey JP. Search-coil head-thrust and caloric tests in Ménière's disease. Acta Otolaryngol 2005;125(8):852-7.

11) Weber KP, Aw ST, Todd MJ, McGarvie LA, Curthoys IS, Halmagyi GM. Head impulse test in unilateral vestibular loss: vestibulo-ocular reflex and catch-up saccades. Neurology 2008;70(6):454-63.

12) Weber KP, Aw ST, Todd MJ, McGarvie LA, Curthoys IS, Halmagyi GM. Horizontal head impulse test detects gentamicin vestibulotoxicity. Neurology 2009;72(16):1417-24.

13) Blödow A, Pannasch S, Walther LE. Detection of isolated covert saccades with the video head impulse test in peripheral vestibular disorders. Auris Nasus Larynx 2013;40(4):348-51.

14) Mantokoudis G, Tehrani AS, Wozniak A, Eibenberger K, Kattah JC, Guede CI, et al. VOR gain by head impulse video-oculography differentiates acute vestibular neuritis from stroke. Otol Neurotol 2015; 36(3):457-65.

15) Hirvonen M, Aalto H, Migliaccio AA, Hirvonen TP. Motorized head impulse rotator for horizontal vestibulo-ocular reflex: Normal responses. Arch Otolaryngol Head Neck Surg 2007;133(2):157-61.

16) Halmagyi GM, MacDougall H, Curthoys IS, McGarvie LA. Video head impulse test diagnoses vestibulotoxicity. Otolaryngol Head Neck Surg 2012;147(2 Suppl):95. 